\title{
Reviews
}

\section{Painless labour: how far have we travelled?}

\author{
Sukhwinder Kaur Bajwa ${ }^{1}$, Sukhminder Jit Singh Bajwa ${ }^{1}$, Kamaljit Singh $^{1}$, Anita Singh ${ }^{1}$
}

Sri Lanka Journal of Obstetrics and Gynaecology 2010; 32: 93-98

\section{Introduction}

Almost every woman in their lifetime bears the pain of parturition since the birth of mankind. The belief that bearing the pain of parturition and delivering a healthy baby makes a woman 'complete' in all aspects is a myth. Given a chance, every woman experiencing the dynamicity of childbirth will want to get rid of the labour pain as soon as possible. History is full of myths and controversies regarding the relief of pain in labour. The concept of modern labour analgesia was born in the early nineteenth century when a woman was administered ether during childbirth by Dr. James Young Simpson. The concept of regional anaesthesia for painless delivery came into existence during mid-twentieth century when the first report for continuous caudal analgesia for childbirth was published by Edward and Hugson ${ }^{1}$. The true perspectives of painless labour came into existence with advancements over the last three decades as the birth of obstetric anaesthesia as a sub-speciality has cemented a permanent place in the field of obstetrics and anaesthesia.

\section{Anatomical and physiological aspects of labour pain}

Labour pain is the result of many complex physiological and psychological interactions, both excitatory and inhibitory. The first stage of labour is associated with diffuse pain which originates from the dilatation and stretching of lower uterine segment and the cervix $x^{2,3}$. Greater dilatation of the vagina and pressure on the perineum is responsible for the more intense somatic pain during the second stage of labour. The small unmyelinated ' $C$ ' visceral fibres ${ }^{4}$ transmit nociception of first stage of labour through lumbar and lower thoracic sympathetic chains to the posterior nerve roots of the 10th, 11th and 12th thoracic nerves and also to 1st lumbar nerve to synapse in the dorsal horn $^{5}$. The second, third and the fourth sacral spinal segment carry pain impulses of 2 nd stage of labour through pudendal nerve. The visceral pain during the

\footnotetext{
${ }^{1}$ Gian Sagar Medical College and Hospital, Banur, Patiala, Punjab, India.

Correspondence: Sukhwinder Kaur Bajwa

E-mail: sukhminder_bajwa2001@yahoo.com
}

two stages of labour is typified by the involvement of the respective dermatomes. The chemical mediators involved are bradykinin, leukotrienes, prostaglandins, serotonin, substance $\mathrm{P}$ and lactic acid ${ }^{6}$.

The thorough and complete anatomical knowledge is an essentiality in understanding the pathophysiologic aspects of labour pain, its transmission and the modalities for its treatment. First stage labour pain can be blocked by paracervical plexus blockade whereas 2 nd stage pain can be abolished by blocking pudendal nerve. Advancements in obstetrical anaesthesia have shifted the previous focus from simply abolishing the labour pain to providing a quality labour analgesia with a minimal of side effects ${ }^{7}$. The year 2007-2008 was declared as the 'Global year against pain in women - Real Women, Real Pain' by the International Association for the Study of Pain (IASP). In the modern era of obstetrical advancements, the emphasis is on providing comprehensive and evidence based management of labour pain, thus improving the quality of labour analgesia ${ }^{7}$. Whichever the stage of labour, the pain associated with it is influenced by many factors which can decrease or increase its severity. To name a few, these include maternal age, parity, maternal condition, the condition of the cervix, the proportional size of the birth canal, etc ${ }^{8}$. The pain is experienced more by the elderly primi-gravida. The cephalo-pelvic disproportion, large size of the baby and occipitoposterior presentation is associated with more pain ${ }^{9,10}$. Dysmenorrhoea, psychological state of the mother, anxious attitude, fear of labour process and apprehensions are also responsible to a certain extent for a lower threshold for bearing labour pain ${ }^{11}$.

\section{Systemic effects of labour pain}

Labour pain as well as tearing of the tissues during labour is associated with direct and indirect effects on mother and fetus.

Respiratory: Pain initiates hyperventilation, increase minute ventilation and increased oxygen consumption. As a result of hypocarbia and respiratory alkalosis due to hyperventilation, the oxygen-haemoglobin dissociation curve is shifted to the left which causes a diminished oxygen transfer to the fetus ${ }^{12}$. 
Cardio-vascular: Labour pain causes a progressive increase in maternal cardiac output primarily due to increase in stroke volume and to a lesser extent maternal heart rate. The maximum increase in cardiac output occurs immediately after delivery as a result of increased venous return associated with relief of venocaval compression and the auto transfusion resulting from uterine involution. Special precautions have to be taken in pregnant patients with heart disease, pulmonary hypertension and pre-eclampsia before resorting to any clinical intervention.

Central nervous system/autonomic nervous system: The sympathetic nervous system gets activated as a result of labour stress and this increases the plasma catecholamine levels ${ }^{13}$. Epinephrine is a tocolytic and physicians have long observed that an apparent dysfunctional labour pattern can be corrected with effective analgesia ${ }^{14}$ Stimulation of pain results in the release of beta-endorphins and ACTH from the anterior pituitary and anxiety further exaggerates this pituitary response ${ }^{15}$. Excessive sympathetic activity may result in in-coordinate uterine action, prolonged labour and abnormal fetal heart rate pattern. Activation of autonomic nervous system also delays gastric emptying and reduces intestinal peristalsis. This effect acquires clinically a very significant aspect in case the parturient has to be taken up for operative delivery under general anaesthesia as there will be a potentially increased risk of pulmonary aspiration.

Psychological: Severe intensity of labour pain may result in serious mental health disturbances that interferes with maternal-neonatal bonding, future sexual relationship and can contribute to postpartum stress disorders ${ }^{16}$.

Metabolic: During labour, glucagon, growth hormone, rennin and ADH level increases while insulin and testosterone level decreases. Circulatory free fatty acids and lactate also increase with a peak level at the time of delivery ${ }^{15}$. Maternal catecholamines may cause fetal acidosis due to low placental blood flow ${ }^{17}$.

Our current understanding of neurophysiologic mechanism of labour pain is fairly superficial. Further research, randomized clinically controlled trials, better understanding of the pain pathways, physiology of neurotransmitters and the knowledge of receptors involved in the complex pain mechanism will help in exploring more opportunities for the effective treatment of labour pain.

\section{Methods of pain relief}

The methods of pain relief can be basically dived into two broad categories:

A. Non-pharmacological

B. Pharmacological
Non-pharmacological: Emotional support, childbirth education, massage, aroma therapy, hydrotherapy, intradermal water injection, biofeedback, TENS (transcutaneous electrical nerve stimulation), acupuncture, acupressure and hypnosis have been promulgated as non-pharmacological methods to relieve pain associated with childbirth ${ }^{18,19}$. However, the number of women studied has been small and there have been no proven scientific data analysis of the quality of pain relief offered by these techniques. There is some evidence suggesting that water immersion during the first stage of labour reduces the use of epidural analgesia. Various controlled trials have concluded that women who received continuous labour support had short labours, fewer operative deliveries, fewer analgesic interventions and greater satisfaction $^{20-22}$.

Intradermal injection of sterile water in doses of 0.05 to $0.1 \mathrm{ml}$ with a tuberculin syringe are administered at lower back, which is quite painful in the beginning but after half an hour the pain fades away also reducing the intensity of labour pain ${ }^{23}$. The use of pharmacologic analgesia decreases to a greater extent using hypnosis on the parturients by a trained individual during childbirth ${ }^{24}$. Few studies have analyzed and concluded that acupuncture therapy during labour resulted in modestly lower pain scores, lesser use of epidural and systemic opioid analgesia ${ }^{25-27}$.

Pharmacological methods: Presently used methods for labour analgesia include inhalational analgesia, systemic narcotics and neuraxial analgesia.

1. Inhalational analgesia: Both gaseous and volatile anaesthetics have been successfully used in the abolition of labour pain. The earlier agents used were ether, chloroform and cyclopropane ${ }^{28,29}$ followed by trichloroethylene and methoxyflurane ${ }^{30}$. These agents can be used in subanaesthetic concentration for provision of analgesia during labour and at the same time maintaining maternal consciousness and avoiding regurgitation or aspiration of stomach contents. These agents readily cross the placental barrier and achieve an equipotent concentration in the fetal blood as that of mother but are rapidly excreted through fetal lungs ${ }^{31}$.

Ether has several side effects including potent emetic effect with a pungent odour. It is also an irritant to the respiratory tract and is explosive so cannot be used in modern times where extensive use of electric cautery is mandatory. Chloroform has dose related side effects namely arrhythmias and liver damage. Methoxyflurane and trichloroethylene have been used for analgesia in labour but have been withdrawn for other non-obstetric reasons. 
The only agent that has survived the test of times is nitrous oxide and is administered as 'Entonox' which is an equal-proportional mixture of (50:50) oxygen and nitrous oxide. Various studies have concluded that Entonox is certainly not a potent analgesic ${ }^{32}$ but some beneficial effects are definitely delivered if it is properly inhaled. It is particularly useful if neuraxial analgesia is contraindicated.

Isoflurane, enflurane, desflurane and sevoflurane are the most recent additions in the armamentarium of an anaesthesiologist. Sevoflurane is one of the latest additions in the group of inhalational fluoride anaesthetics which has got a very rapid onset and termination of action. This property makes it somewhat an ideal inhalational anaesthetic agent for labour analgesia. It is delivered by a specific vaporizer with oxygen acting as carrier gas and it is delivered in a dose of $0.8-1 \%$ for the purpose of abolition of labour pain. It is being extensively evaluated for labour analgesia but more studies are needed to establish it as a safe agent for painless labour ${ }^{33,34}$.

\section{Systemic narcotics/analgesics:}

Pethidine (meperidine): It is one of the most commonly used opioid derivatives for a long time now for the relief of pain. However, its effect on the general progress of labour is quite controversial and various studies have concluded that pethidine should not be administered in parturients with cervical dystocia as there is no benefit and that there is a greater risk of neonatal adverse outcome.

Morphine: It has got a long duration of action and is out of favour nowadays because of possible respiratory depression in the newborn, addiction and nausea and vomiting.

Ketamine: For relief of labour pain it has to be administered in higher doses (anaesthetic doses) which can compromise the airway because of diminution of airway reflexes.

Fentanyl: It is a highly lipid soluble synthetic opioid with 100 times higher potency than that of morphine and acts on the mu receptors ${ }^{35}$. The peak analgesic effect occurs within 3-5 minutes and the duration of the effect lasts for approximately 30 minutes. It can be administered in boluses of 25-50 mcg every hour or as a continuous infusion of 0.25 $\mathrm{mcg} / \mathrm{kg} / \mathrm{hr}$.

Tramadol: For labour pain it has been prescribed in doses of $50-100 \mathrm{mg} 4$ hourly. It has no clinically significant respiratory depression but incidence of nausea is more common with tramadol than with pethidine or morphine ${ }^{36}$.
Nalbuphine: It is a synthetic mixed mu-agonist/ antagonist and a kappa agonist. It is administered in doses of 10-20 mg intramuscularly for the relief of labour pain. Sedation and dysphoria are the main disadvantages of this drug.

Butorphanol: It is a synthetic narcotic which is five times as potent as morphine and 40 times as potent as pethidine. The dose of butorphanol is $1-2 \mathrm{mg}$ intramuscularly. Neonatal respiratory depression is reported to be less than with pethidine ${ }^{37}$. It is not frequently used for labour analgesia as it produces greater sedation.

Remifentanil: It is an ultra-short acting synthetic opioid with a rapid onset of action and a half life of 6 minutes. It can readily cross placenta but is extensively metabolized by the fetus. The recommended infusion dose is $0.025 \mathrm{mcg} / \mathrm{kg} / \mathrm{min}$ which can be increased in incremental manner up to a maximum dose of $0.15 \mathrm{mcg} / \mathrm{kg} / \mathrm{min}$.

Whenever one intends to use opioid for abolition of labour pain, they should be ready with injection naloxone which is the opioid antagonist of choice for reversing the neonatal effects of maternal opioid administration. The dose of naloxone for reversing neonatal respiratory depression is $0.1 \mathrm{ml} / \mathrm{kg}$ intramuscularly while for maternal respiratory depression, the dose is $0.4 \mathrm{mg}$ intravenously ${ }^{38}$.

\section{Neuraxial analgesia}

Central neuraxial analgesia is the most versatile, complete and effective method of pain relief during labour and is the gold standard technique in obstetrics without maternal or fetal sedation ${ }^{39}$. It has been increasingly used for the last three decades as more and more women are using these services in the western countries but the scenario is not as robust in the developing nations ${ }^{40}$. The term 'walking' or 'mobile' epidural analgesia was first coined to describe the combined spinal epidural opioid analgesia because motor functions were maintained and the ability to walk was not impaired ${ }^{41}$.

Advantages of neuraxial labour analgesia include complete analgesia, no maternal sedation, abolition of deleterious reflexes associated with pain and the procedure can be converted to complete anaesthesia in case of operative intervention. Central neuraxial blockade comes with certain disadvantages also which includes availability of skilled anaesthesiologist, maternal hypotension, and decreased utero-placental perfusion, prolonged second stage of labour and possible increased risk of instrument delivery ${ }^{7}$.

The technical advancements and availability of newer drugs and adjuvants have refined the procedure of central neuraxial blockade. 
a. Combined spinal epidural analgesia: It involves the administration of spinal anaesthesia through epidural needle and result in rapid onset and profound analgesia from subarachnoid injection and later prolongation of labour analgesia through epidural catheter ${ }^{42}$. As per the guidelines of Obstetrical Anaesthesia Association of United Kingdom (2005) CSEA is indicated only in specific circumstances.

b. Low dose epidural regimes: Recently, use of low concentration of the local anaesthetics has reduced the total dose of local anaesthetics and its associated side effects ${ }^{43}$, thus producing a greater margin of safety and allowing fine tuning of labour analgesia. An increased proportion of vaginal deliveries have been reported when using low dose epidural analgesia as was also established by the COMET study published in the Lancet in $2001^{44,45}$.

c. Maintenance of neuraxial labour analgesia intrapartum: It can be achieved by continuous infusion of local anaesthetics, intermittent boluses or patient controlled analgesia ${ }^{46}$. A dilute solution of bupivacaine or ropivacaine combined with fentanyl or sufentanyl is commonly used. The dosage recommended for labour analgesia is $0.0625 \%$ bupivacaine with $2 \mathrm{mcg} / \mathrm{ml}$ of fentanyl infusing at 10-12 $\mathrm{ml} / \mathrm{hr}$ which is safe for both the mother and the neonate ${ }^{47}$.

d. Patient controlled epidural analgesia: It is considered a novel method for control of labour pain with a minimal dosage of local anaesthetics required as per titration by the patient. The essential component of drug delivery system includes intermittent boluses, continuous background infusion and a minimum lockout interval.

e. Non-narcotic adjuvant for labour analgesia: Clonidine and dexmedetomidine are alpha-2 agonists that can be used as adjuvant to local anaesthetics and they act at the dorsal horn of the spinal cord to produce analgesia. Addition of adrenaline as adjuvant helps in intensifying and prolonging the neural blockade. Similarly, ketamine and midazolam have been extensively evaluated as neuraxial adjuvant for early onset and prolongation of neuraxial analgesia.

\section{Present scenario and the old controversies}

There is no association of increased operative intervention in the patients receiving labour analgesia as established by Cochrane database systemic trials ${ }^{48}$. Though, there may be slight prolongation of the total duration of labour COMET study also stresses upon increased proportion of vaginal deliveries when low dose epidural regimes are used $^{44}$.
Few earlier studies have shown that incidence of caesarean sections increases when epidural analgesia is used early in the labour ${ }^{49}$. But few other studies including that of Wong et al found no increase in incidence of operative deliveries in patients receiving epidural analgesia early in the labour $48,50,51$.

Another major controversy is the related incidence of backache and neuraxial anaesthesia but the recent trials and studies have established that there is no significant difference between the incidence of backache and the type of labour analgesia received ${ }^{52}$. Similarly, the post dural puncture headache has reduced drastically with increasing use of smaller gauge (25-27 G) spinal needles. The infection rate (meningitis) is not significant in parturients where neuraxial analgesia was employed. These controversies will keep haunting the obstetricians and the anaesthesiologists for a long time to come especially in the obstetrical set-up of developing countries.

Labour analgesia has to be popularized and should be delivered to every demanding and desirous mother who really wants a painless process of parturition. In a world of equivalent status for both genders, society should also respect every decision of a parturient and efforts should be made to make the process of perpetuation more comfortable and pleasant for the womenfolk.

\section{References}

1. Hingson RA, Edwards WB. Continuous caudal analgesia: An analysis of the first ten thousand confinements thus managed with the report of the authors' first thousand cases. JAMA 1943; 123: 538-46.

2. Wong CA. Obstetric Pain. In: Ballantyne JC, Rathmell JP, Fishman SM, eds. Bonica's Management of Pain. 4th ed. Philadelphia: Lippincott Williams \& Wilkins; In press.

3. Pan $P$, Eisenach JC. The pain of childbirth and its effect on the mother and the fetus. In: Chestnut DH, Polley LS, Tsen LC, Wong CA, eds. Obstetric Anesthesia Principles and Practice. 4th ed. Philadelphia: Elsevier Mosby; 2009: 387404.

4. Ward ME. Acute pain and the obstetric patient: recent developments in analgesia for labour and delivery. International Anaesthesiology Clinics 1997; 35: 83-103.

5. Bonica JJ. Peripheral mechanisms and pathways of parturition pain. British Journal of Anaesthesia 1979; 51 (Supplement): S3-S9.

6. Brownridge $P$. The nature and consequences childbirth pain. European Journal of Obstetrics, Gynaecology and Reproductive Biology 1995; 59: S9-S15.

7. Wong CA. Advances in labour analgesia. Int JWomens Health 2009; 1: 139-54.

8. Sheiner E, Sheiner EK, Shoham-Vardi I. The relationship between parity and labour pain. Int J Gynaecol Obstet 1998; 63(3): 287-8. 
9. Hess PE, Pratt SD, Soni AK, Sarna MC, Oriol NE. An association between severe labour pain and cesarean delivery. Anesth Analg 2000; 90(4): 881-6.

10. Alexander JM, Sharma SK, McIntire DD, Wiley J, Leveno $\mathrm{KJ}$. Intensity of labour pain and caesarean delivery. Anesth Analg 2001; 92(6): 1524-8.

11. Lang AJ, Sorrell JT, Rodgers CS, Lebeck MM. Anxiety sensitivity as a predictor of labour pain. Eur J Pain 2006; 10(3): 263-70.

12. Mahomed K, Gulmezoglu AM, Nikodem VC, et al. Labour experience, maternal mood and cortisol and catecholamine levels in low-risk primiparous women. Journal of Psychosomatic Obstetrics and Gynaecology 1995; 16: 181-6.

13. Lederman RP, McCann DS, Work B Jr, Huber MJ. Endogenous plasma epinephrine and nor epinephrine in last-trimester pregnancy and labor. Am J Obstet Gynecol 1977; 129(1): 5-8.

14. Moir DD, Willocks J. Management of in coordinate uterine action under continuous epidural analgesia. Br Med J1967; 3: $396-400$.

15. Bonica JJ. The nature of pain in parturition. In: Vanzundert A and Ostheimer GW (eds.) Pain Relief and Anaesthesia in Obstetrics 1996; pp19-52. New York: Churchill Livingstone

16. Ballard CG, Stanley AK, Brockington IF. Post-traumatic stress disorder (PTSD) after childbirth. Br J Psychiatry 1995; 166(4): 525-8.

17. Irestedt L, Lagercrantz H, Belfrage P. Causes and consequences of maternal and fetal sympatho-adrenal activation during parturition. Acta Obstetrica et Gynecologica Scandinavica 1995; 118(Supplement): S111-S115.

18. Dowswell T, Bedwell C, Lavender T, Neilson JP. Transcutaneous electrical nerve stimulation (TENS) for pain relief in labour. Cochrane Database Syst Rev 2009; (2):CD007214.

19. Simkin PP, O'hara M. Nonpharmacologic relief of pain during labor: systemic reviews of five methods. Am J Obstet Gynecol 2002; 186: 5; S131-59.

20. Simkin PP, O'Hara M. Nonpharmacologic relief of pain during labor: systematic reviews of five methods. Am J Obstet Gynecol 2002; 186(5 Suppl Nature): S131-S159.

21. Hodnett ED, Gates S, Hofmeyr GJ, Sakala C. Continuous support for women during childbirth. Cochrane Database Syst Rev 2007; (3): CD003766.

22. McGrath SK, Kennell JH. A randomized controlled trial of continuous labor support for middle-class couples: effect on cesarean delivery rates. Birth 2008; 35(2): 92-97.

23. Huntley AL, Coon JT, Ernst E. Complementary and alternative medicine for labor pain: a systematic review. Am J Obstet Gynecol 2004; 191(1): 36-44.

24. Smith CA, Collins CT, Cyna AM, Crowther CA. Complementary and alternative therapies for pain management in labour. Cochrane Database Syst Rev 2006; (4):CD003521.

25. Skilnand E, Fossen D, Heiberg E. Acupuncture in the management of pain in labor. Acta Obstet Gynecol Scand 2002; 81(10): 943-8.

26. Borup L, Wurlitzer W, Hedegaard M, Kesmodel US,
Hvidman L. Acupuncture as pain relief during delivery: a randomized controlled trial. Birth 2009; 36(1): 5-12.

27. Nesheim BI, Kinge R, Berg B, et al. Acupuncture during labor can reduce the use of meperidine: a controlled clinical study. Clin J Pain 2003; 19(3): 187-91.

28. Moya F. Use of chloroform inhaler in obstetrics. NY State Journal of Medicine 1961; 61: 421-9.

29. Shnider SM, Moya F, Thorndike V, Bossers A, Morishima $\mathrm{H}$, James LS. Clinical and biochemical studies of cyclopropane analgesia in obstetrics. Anaesthesiology 1963; 24: 11-17.

30. Major V, Rosen M, Mushin WW. Methoxyflurane as an obstetric analgesic: a comparison with trichloroethylene. British Medical Journal 1996; ii: 1554-61.

31. Vanner RG. Mechanisms of regurgitation and its prevention with cricoids pressure. International Journal of Obstetric Anaesthesia 1993; 2: 207-15.

32. Rosen MA. Nitrous oxide for relief of labor pain: a systematic review. Am J Obstet Gynecol 2002; 186: S110-26.

33. Yeo ST, Holdcroft A, Yentis SM, Stewart A, Bassett P. Analgesia with sevoflurane in labour. II. Sevoflurane compared with entonox for labour analgesia. $\mathrm{Br} \mathrm{J}$

34. Pandya ST. Labour analgesia: recent advances. Indian J Anaesth 2010; 54: 400-8.

35. Rayburn W, Rathke A, Leuschen MP, Chleborad J, Weidner W. Fentanyl citrate analgesia during labor. Am J Obstet Gynecol 1989; 161: 202-6.

36. Prasertsawat PO, Herabutiya Y, Chaturachinda K. Obstetric analgesia: comparison between tramadol, morphine and pethidine. Current Therapeutic Research 1986; 40:1022-8.

37. Quilligan EJ, Keejan KA, Donahue MG. Double blind comparison of intravenously injected butorphanol and meperidine in parturients. International Journal of Obstetrics 1980; 18: 363-6.

38. Chestnut DH. Chestnut's Obstetric Anesthesia: Principles and Practice. In: Chestnut DH, Polley LS, Tsen LC, Wong CA, editors. Philadelphia PA: Mosby Elsevier; 2009. p405501.

39. Hawkins JL. Epidural analgesia for labour and delivery. $N$ Engl J Med 2010; 362: 1503-10.

40. Bucklin BA, Hawkins JL, Anderson JR, Ullrich FA. Obstetric anesthesia workforce survey: twenty-year update. Anesthesiology 2005; 103(3): 645-53.

41. Collis RE, Baxandall ML, Srikantharajah ID, Edge G, Kadim MY, Morgan BM. Combined spinal epidural analgesia with ability to walk throughout labour. Lancet 1993; 341(8847): 767-8.

42. MacArthur AJ, Ostheimer GW. What's New in Obstetric Anesthesia? Lecture. Anesthesiology 2008; 108: 777-85.

43. Lacassie HJ, Habib AS, Lacassie HP, Columb MO. Motor blocking minimum local anesthetic concentrations of bupivacaine, levobupivacaine, and ropivacaine in labor. Reg Anesth Pain Med 2007; 32: 323-9.

44. Comparative Obstetric Mobile Epidural Trial (COMET) Study Group UK 2001. Effect of low-dose mobile versus traditional epidural techniques on mode of delivery: a randomized controlled trial. Lancet 2001; 358: 19-23. 
45. Hart EM, Ahmed N, Buggy DJ. Comparison of bupivacaine $0.25 \%$ vs low dose mixtures: impact study. Int J Obstet Anesth 2003; 12: 4-8.

46. Leo S, Sia AT. Maintaining labour epidural analgesia: what is the best option? Curr Opin Anaesthesiol 2009; 21: 263-9.

47. Chestnut DH, Laszewski LJ, Pollack KL, Bates JN, Manago NK, Choi WW. Continuous epidural infusion of $0.0625 \%$ bupivacaine $-0.0002 \%$ fentanyl during second stage of labour. Anesthesiology 1990; 72: 613-8.

48. Leighton BL, Halpern SH. The effect of epidural analgesia on labor, maternal and neonatal outcomes: a systematic review. Am J Obstec Gynecol 2002; 186: S69-77.
49. Thorp JA, Hu DH, Albin RM, McNitt J, Meyer BA, Cohen GR, et al. A randomized, controlled, prospective trial. Am J Obstet Gynecol 1993; 169: 851-8.

50. Wong CA, Scavone BM, Peaceman AM, McCarthy RJ, Sullivan JT, Diaz NT, et al. The risk of caesarean delivery in neuraxial analgesia given early vs. late in labour. $N$ Engl J Med 2005; 352: 655-65.

51. Sharma SK, McIntire DD, Wiley J, Leveno KJ. Labor analgesia and cesarean delivery: an individual patient metaanalysis of nulliparous women. Anesthesiology 2004; 100(1): 142-8.

52. Lim Y, Sia AT. Dispelling the myths of epidural pain relief in childbirth. Singapore Med J 2006; 47: 1096. 